\title{
Le droit et la raison pour apprivoiser la mondialisation?
}

\section{Jean Martin}

Dr méd., membre de la rédaction

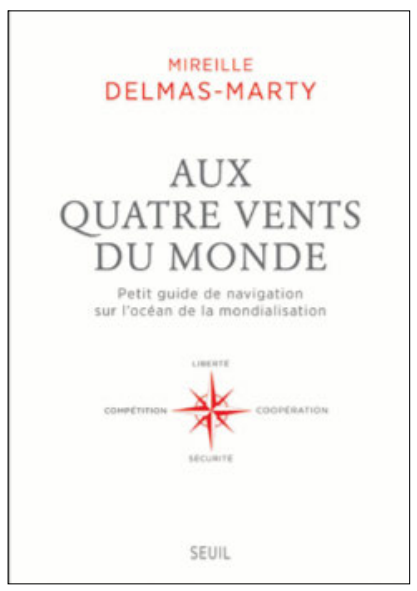

Mireille Delmas-Marty Aux quatre vents du monde

Petit guide de navigation sur l'océan de la mondialisation Paris: Seuil; 2016.

150 pages. $26.40 \mathrm{CHF}$.

ISBN 978-2-021-18589-8

«Nous vivons dans une société désenchantée d'où l'esprit aurait été chassé par la matière, la raison numérisée ne laissant guère de place au rêve. Comment transformer les interdépendances subies en projet commun?» Réponse: en mobilisant les forces imaginantes du droit, explique dans un ouvrage stimulant Mireille Delmas-Marty, professeure de droit. Son propos est la gestion de la mondialisation dans un sens de gouvernance mondiale, au vu de la montée du terrorisme, des migrations, des dérèglements climatiques et de la suite à donner à la COP 21 de Paris de 2015. En soulignant qu'une telle gouvernance doit être plus que transnationale mais encore transgénérationnelle (si juste!).

Des idées iconoclastes... «Schizophrénie des Etats, qui affichent une posture universaliste mais pratiquent l'exploitation effrénée des énergies fossiles. Cela reflète une contradiction profonde entre les sociétés faites d'individus, animés chacun d'un désir de bien-être, et les écosystèmes.» Emprunté à Y. C. Zarka: «Si nous vou- tie des individus que nous connaissons?» Question que je me pose de longue date... Mais abolir - ou pour le moins aménager - la démocratie n'est-ce pas aller vers des régimes autoritaires?

Pour l'auteure, un consensus mondial devrait être possible, «en substituant à la trilogie traditionnelle (exécutif, législatif, judicaire) une trilogie nouvelle: vouloir, savoir et pouvoir. Le vouloir des acteurs civiques et sociétaux, le savoir des scientifiques, le pouvoir des acteurs politiques et économiques.» Insistant aussi sur le "savoir du vécu", celui notamment des peuples autochtones et des populations précarisées, dont il importe de tenir compte. On sait les débats actuels sur expertise et experts. Delmas-Marty relève que le nombre limité d'experts compétents dans certains domaines risque de rendre les conflits d'intérêts inévitables. Alors: «Un expert vraiment indépendant est-il un expert incompétent?» Une problématique aussi dans le domaine biomédical.

A propos de transhumanisme: «Faut-il autoriser ce type de technologies au nom de la liberté ou l'interdire au nom d'une certaine vision de l'humanité?» Que penser quand on envisage d'administrer aux pilotes de drones de combat une pilule pour réduire l'empathie envers les cibles? Nécessaire de «repenser les limites, en rappelant que la liberté suppose une certaine 'indétermination humaine', nécessaire à la survie car elle favorise la créativité et l'adaptabilité, et institue l'homme dans sa responsabilité.»

Pour équilibrer les excès d'une mondialisation qui détruit au nom de la liberté d'entreprendre, DelmasMarty discute quatre principes, reliant deux notions chacun: liberté ET sécurité, pour l'égale dignité de tous compétition ET coopération, pour une solidarité planétaire; innovation ET conservation (avec le principe de précaution, mieux appelé 'devoir d'anticipation'); exclusion ET intégration. En rapport avec le dernier mentionné: «La cohésion sociale doit être comprise non dans une perspective pluraliste de juxtaposition, qui aboutit à des ghettos, mais comme un pluralisme ordonné, ou harmonisé, qui admet des différences.» Jusqu'ici, «les peuples adoptaient des déclarations d'indépendance. Aujourd'hui il s'agit de reconnaître les 
interdépendances et de les transformer en un destin commun - sans qu'il s'agisse de vouloir un universalisme fusionnel improbable.» Et la question à dix mille dollars (ou dix mille milliards de dollars): «A l'étape anthropocène, où l'humanité devient une force tellurique influençant l'avenir de la planète, elle devrait être capable d'influencer son propre avenir»! Marqué au coin du bon sens, non? Pourtant, à l'ère post-factuelle et postvérité dans laquelle nous sommes entrés (campagne électorale sur le Brexit, présidentielle récente aux EtatsUnis), qui prendrait le pari de la sagesse? «Peut-être avons-nous surévalué la place des raisonnements logiques et sous-évalué l'importance du vieux paléo-cortex cérébral?» Encore faut-il «que les citoyens apprennent à résister aux automatismes qui, sous le poids de l'émotion, échappent à la raison". C'est exactement cela. Qui en ouvrira le chemin? 